\title{
SARS and MERS: recent insights into emerging coronaviruses
}

Emmie de Wit ${ }^{1}$, Neeltje van Doremalen ${ }^{1}$, Darryl Falzarano ${ }^{2}$ and Vincent J. Munster ${ }^{1}$

Abstract | The emergence of Middle East respiratory syndrome coronavirus (MERS-CoV) in 2012 marked the second introduction of a highly pathogenic coronavirus into the human population in the twenty-first century. The continuing introductions of MERS-CoV from dromedary camels, the subsequent travel-related viral spread, the unprecedented nosocomial outbreaks and the high case-fatality rates highlight the need for prophylactic and therapeutic measures. Scientific advancements since the 2002-2003 severe acute respiratory syndrome coronavirus (SARS-CoV) pandemic allowed for rapid progress in our understanding of the epidemiology and pathogenesis of MERS-CoV and the development of therapeutics. In this Review, we detail our present understanding of the transmission and pathogenesis of SARS-CoV and MERS-CoV, and discuss the current state of development of measures to combat emerging coronaviruses.

Nosocomial transmission Transmission of an infectious agent by staff, equipment or the environment in a health care setting.
${ }^{1}$ Laboratory of Virology, Division of Intramural Research, National Institute of Allergy and Infectious Diseases, National Institutes of Health, Rocky Mountain Laboratories, Hamilton, Montana 59840, USA. ${ }^{2}$ Vaccine and Infectious Disease Organization International Vaccine Centre and Department of Veterinary Microbiology, University of Saskatchewan, 120 Veterinary Road, Saskatoon, Saskatchewan S7N 5E3, Canada.

Correspondence to V.J.M. vincent.munster@nih.gov
This century has seen the global spread of two previously unknown coronaviruses. In November 2002, the first known case of severe acute respiratory syndrome (SARS) occurred in Foshan, China ${ }^{1}$. New cases emerged in mainland China, and by February 2003, more than 300 cases had been reported, around one-third of which were in health care workers ${ }^{1}$. Individuals who were infected and subsequently travelled spread the outbreak to Hong Kong $^{2}$ and from there to Vietnam, Canada and several other countries ${ }^{3}$. In March 2003, the WHO established a network of laboratories to determine the causative agent of SARS. A remarkable global effort led to the identification of SARS coronavirus (SARS-CoV) in early April of that year ${ }^{4-6}$. By July 2003 and after a total of 8,096 reported cases, including 774 deaths in 27 countries $^{7}$, no more infections were detected, and the SARS pandemic was declared to be over. Five additional SARS cases, resulting from zoonotic transmission, occurred in December 2003-January 2004 (REF. 8), but no human SARS cases have been detected since. Measures of infection control, rather than medical interventions, ended the SARS pandemic. However, certain SARS-CoV-like viruses found in bats have recently been shown to be able to infect human cells without prior adaptation ${ }^{9,10}$, which indicates that SARS could re-emerge.

In June 2012, 10 years after the first emergence of SARS-CoV, a man in Saudi Arabia died of acute pneumonia and renal failure. A novel coronavirus, Middle East respiratory syndrome coronavirus (MERS-CoV), was isolated from his sputum ${ }^{11}$. A cluster of cases of severe respiratory disease had occurred in April 2012 in a hospital in Jordan and was retrospectively diagnosed as
MERS $^{12}$, and a cluster of three cases of MERS in the UK was identified in September 2012 (REF. 13). MERS-CoV continued to emerge and spread to countries outside of the Arabian Peninsula as a result of travel of infected persons; often, these imported MERS cases resulted in nosocomial transmission. In May 2015, a single person returning from the Middle East started a nosocomial outbreak of MERS in South Korea that involved 16 hospitals and 186 patients ${ }^{14}$. As of 26 April 2016, there have been 1,728 confirmed cases of MERS, including 624 deaths in 27 countries $^{15}$.

This Review highlights the pandemic and epidemic potential of emerging coronaviruses and discusses our current knowledge of the biology of SARS-CoV and MERS-CoV, including their transmission, their pathogenesis and the development of medical countermeasures. Key features of these viruses are the dominance of nosocomial transmission, and pathogenesis that is driven by a combination of viral replication in the lower respiratory tract and an aberrant host immune response. Several potential treatments for SARS and MERS have been identified in animal and in vitro models, including small-molecule protease inhibitors, neutralizing antibodies and inhibitors of the host immune response. However, efficacy data from human clinical trials are lacking but are needed to move these potential countermeasures forward.

\section{Replication of SARS-CoV and MERS-CoV}

SARS-CoV and MERS-CoV belong to the Coronavirus genus in the Coronaviridae family and have large, positive-sense RNA genomes of $27.9 \mathrm{~kb}$ and $30.1 \mathrm{~kb}$, 
Proofreading

The correction of errors that are acquired during the replication of DNA or RNA respectively (FIG. 1a). Similarly to all viruses in the order Nidovirales, SARS-CoV and MERS-CoV have a unique coding strategy: two-thirds of the viral RNA is translated into two large polyproteins, and the remainder of the viral genome is transcribed into a nested set of subgenomic mRNAs $^{16,17}$ (FIG. 1 b). The two polyproteins, ppla and pplab, encode 16 non-structural proteins (nsp1-nsp16) ${ }^{18}$ that make up the viral replicase-transcriptase complex. The polyproteins are cleaved by two proteases, papainlike protease (PLpro; corresponding to nsp3) and a main protease, 3C-like protease (3CLpro; corresponding to nsp5). The nsps rearrange membranes that are derived from the rough endoplasmic reticulum (RER) into double-membrane vesicles, in which viral replication and transcription occur ${ }^{19}$. One unique feature of coronaviruses is the exoribonuclease (ExoN) function of nsp14 (REF. 20), which provides the proofreading capability required to maintain a large RNA genome without the accumulation of detrimental mutations ${ }^{21,22}$. SARS-CoV and MERS-CoV transcribe 12 and 9 subgenomic RNAs,
Genomes

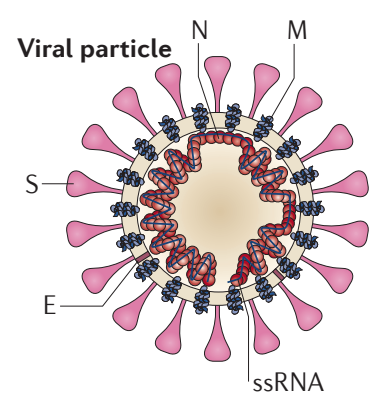

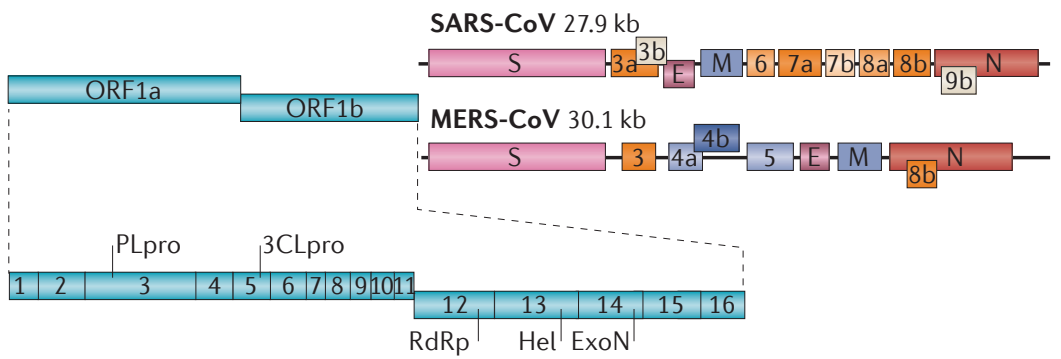

b

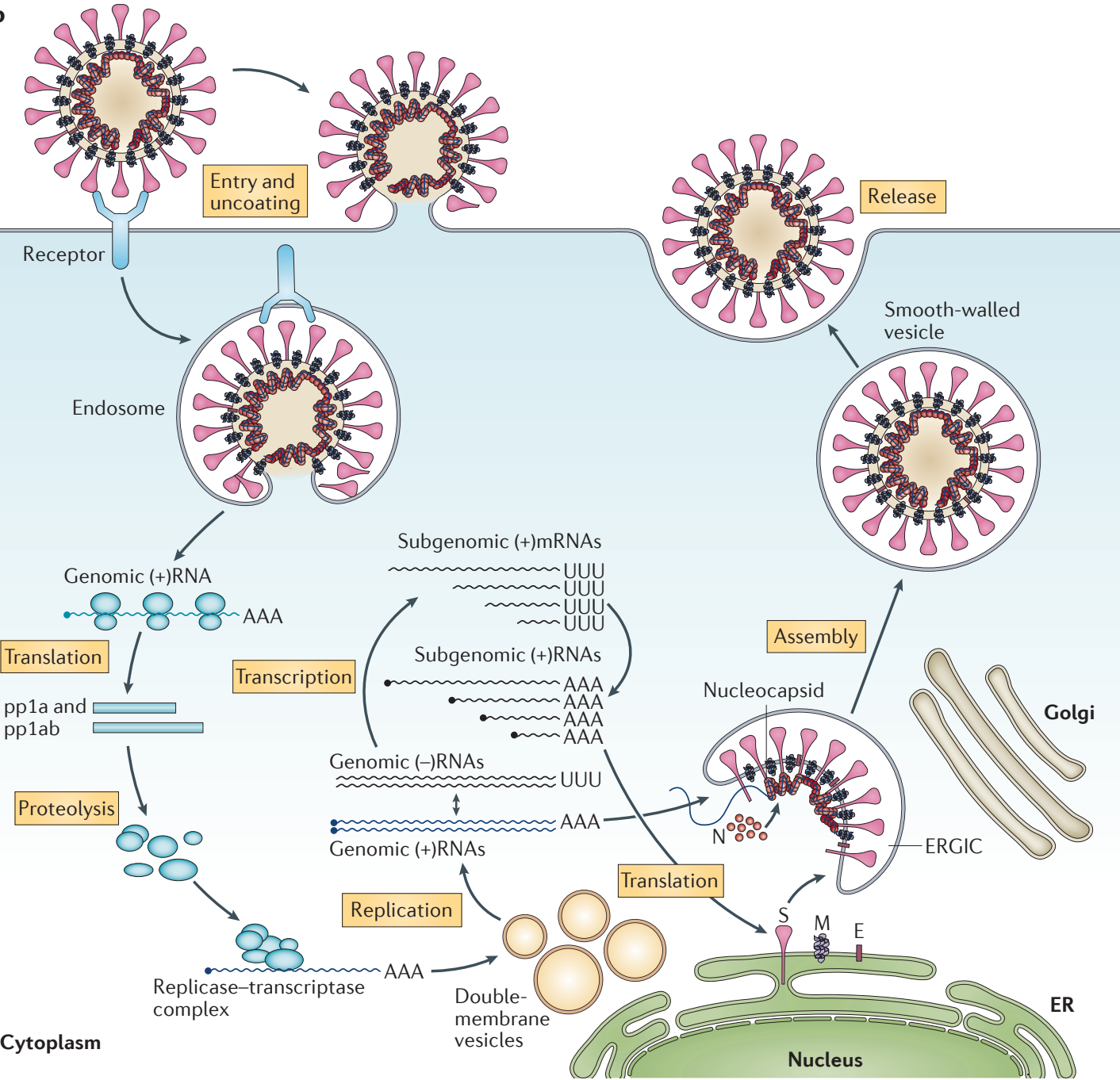


ER-Golgi intermediate compartment (ERGIC). A cellular compartment that facilitates transport between the endoplasmic reticulum (ER) and the Golgi complex.

\section{Super spreaders}

Infected individuals who each infect a disproportionately large number of secondary cases. respectively, and these encode the four structural proteins spike (S), envelope (E), membrane (M) and nucleocapsid $(\mathrm{N})$, as well as several accessory proteins that are not involved in viral replication but interfere with the host innate immune response or are of unknown or poorly understood function.

The envelope spike glycoprotein binds to its cellular receptor, angiotensin-converting enzyme 2 (ACE2) for SARS-CoV and dipeptidyl peptidase 4 (DPP4) for MERS-CoV ${ }^{23}$. After membrane fusion, either directly with the host cell membrane or with the endosome membrane, the viral RNA genome is released into the cytoplasm, and the RNA is uncoated to allow translation of the two polyproteins, transcription of the subgenomic RNAs and replication of the viral genome (FIG. 1b). Newly formed envelope glycoproteins are inserted in the RER or Golgi membranes; genomic RNA and nucleocapsid proteins combine to form nucleocapsids, and the viral particles bud into the ER-Golgi intermediate compartment (ERGIC). Virion-containing vesicles subsequently fuse with the plasma membrane to release the virus ${ }^{24}$.

\section{Reservoirs and transmission}

The first indication of the source of SARS-CoV was the detection of the virus in masked palm civets and a raccoon dog and the detection of antibodies against the virus in Chinese ferret badgers in a live-animal market in Shenzhen, China ${ }^{25}$. However, these animals were only incidental hosts, as there was no evidence for the circulation of SARS-CoV-like viruses in palm civets in the wild or in breeding facilities ${ }^{26}$. Rather, bats are the reservoir of a wide variety of coronaviruses, including SARS-CoV-like and MERS-CoV-like viruses ${ }^{27}$ (FIG. 2).

Figure 1 | SARS-CoV and MERS-CoV structure and replication. a| The single-stranded RNA (ssRNA) genomes of severe acute respiratory syndrome coronavirus (SARS-CoV) and Middle East respiratory syndrome coronavirus (MERS-CoV) encode two large polyproteins, pp1a and pp1ab, which are proteolytically cleaved into 16 non-structural proteins (nsps), including papain-like protease (PLpro), 3C-like protease (3CLpro), RNA-dependent RNA polymerase (RdRp), helicase (Hel) and exonuclease (ExoN). An additional 9-12 ORFs are encoded through the transcription of a nested set of subgenomic RNAs. SARS-CoV and MERS-CoV form spherical particles that consist of four structural proteins. The envelope glycoprotein spike (S) forms a layer of glycoproteins that protrude from the envelope. Two additional transmembrane glycoproteins are incorporated in the virion: envelope (E) and membrane (M). Inside the viral envelope resides the helical nucleocapsid, which consists of the viral positive-sense RNA ((+)RNA) genome encapsidated by protein nucleocapsid (N). b | Following entry of the virus into the host cell, the viral RNA is uncoated in the cytoplasm. ORF1a and ORF1ab are translated to produce pp1a and pp1ab, which are cleaved by the proteases that are encoded by ORF1a to yield $16 \mathrm{nsps}$ that form the RNA replicase-transcriptase complex. This complex localizes to modified intracellular membranes that are derived from the rough endoplasmic reticulum (ER) in the perinuclear region, and it drives the production of negative-sense RNAs ((-)RNAs) through both replication and transcription. During replication, full-length (-)RNA copies of the genome are produced and used as templates for full-length (+)RNA genomes. During transcription, a subset of 7-9 subgenomic RNAs, including those encoding all structural proteins, is produced through discontinuous transcription. In this process, subgenomic (-)RNAs are synthesized by combining varying lengths of the $3^{\prime}$ end of the genome with the $5^{\prime}$ leader sequence necessary for translation. These subgenomic (-)RNAs are then transcribed into subgenomic (+)mRNAs. Although the different subgenomic mRNAs may contain several ORFs, only the first ORF (that closest to the $5^{\prime}$ end) is translated. The resulting structural proteins are assembled into the nucleocapsid and viral envelope at the ER-Golgi intermediate compartment (ERGIC), followed by release of the nascent virion from the infected cell.
Thus, the search for the reservoir of MERS-CoV initially focused on bats, but a serological survey in dromedary camels from Oman and the Canary Islands showed a high prevalence of MERS-CoV-neutralizing antibodies in these animals ${ }^{28}$. In addition, MERS-CoV RNA was detected in swabs that were collected from dromedary camels at a farm in Qatar that was linked to two human cases of MERS, and infectious virus was isolated from dromedary camels in Saudi Arabia and Qatar ${ }^{29-32}$. Serological evidence for the circulation of a MERS-CoV-like virus in dromedary camels has been obtained in the Middle East, Eastern Africa and Northern Africa, dating back as far as 1983 (REF. 33). Dromedary camels in Saudi Arabia harbour several viral genetic lineages ${ }^{34}$, including those that have caused human outbreaks. Taken together, these data strongly point to the role of dromedary camels as a reservoir for MERS-CoV. The ubiquity of infected dromedary camels close to humans and the resulting continuing zoonotic transmission may explain why MERS-CoV continues to cause infections in humans, whereas SARS-CoV, without the continuing presence of an infected intermediate host and with relatively infrequent human-bat interactions, has caused no more infections in humans.

Human-to-human transmission of SARS-CoV and MERS-CoV occurs mainly through nosocomial transmission; $43.5-100 \%$ of MERS cases in individual outbreaks were linked to hospitals, and very similar observations were made for some of the SARS clusters $^{35,36}$. Transmission between family members occurred in only $13-21 \%$ of MERS cases and $22-39 \%$ of SARS cases. Transmission of MERS-CoV between patients was the most common route of infection (62-79\% of cases), whereas for SARS-CoV, infection of health care workers by infected patients was very frequent $(33-42 \%)^{35}$. The predominance of nosocomial transmission is probably due to the fact that substantial virus shedding occurs only after the onset of symptoms ${ }^{37,38}$, when most patients are already seeking medical care ${ }^{39}$. An analysis of hospital surfaces after the treatment of patients with MERS showed the ubiquitous presence of viral RNA in the environment for several days after patients no longer tested positive ${ }^{40}$. Moreover, many patients with SARS or MERS were infected through super spreaders ${ }^{14,35,37,41-43}$.

\section{The pathogenesis of SARS-CoV and MERS-CoV}

The clinical courses of SARS and MERS are remarkably similar, although there are subtle differences (BOX 1). Owing to the current sparsity of data on human MERS$\mathrm{CoV}$ infections ${ }^{44}$, the pathogenesis of this virus is poorly understood; however, similar mechanisms may underlie the pathogenesis of both MERS and SARS.

The binding of spike protein to ACE2 and the subsequent downregulation of this receptor contribute to lung injury during SARS ${ }^{45}$. Although it seems counterintuitive that receptor downregulation would increase pathology, it has been shown that ACE2 can protect against acute lung injury. The downregulation of ACE2 results in the excessive production of angiotensin II by the related enzyme ACE, and it has been suggested that the stimulation of type 1a angiotensin II receptor 


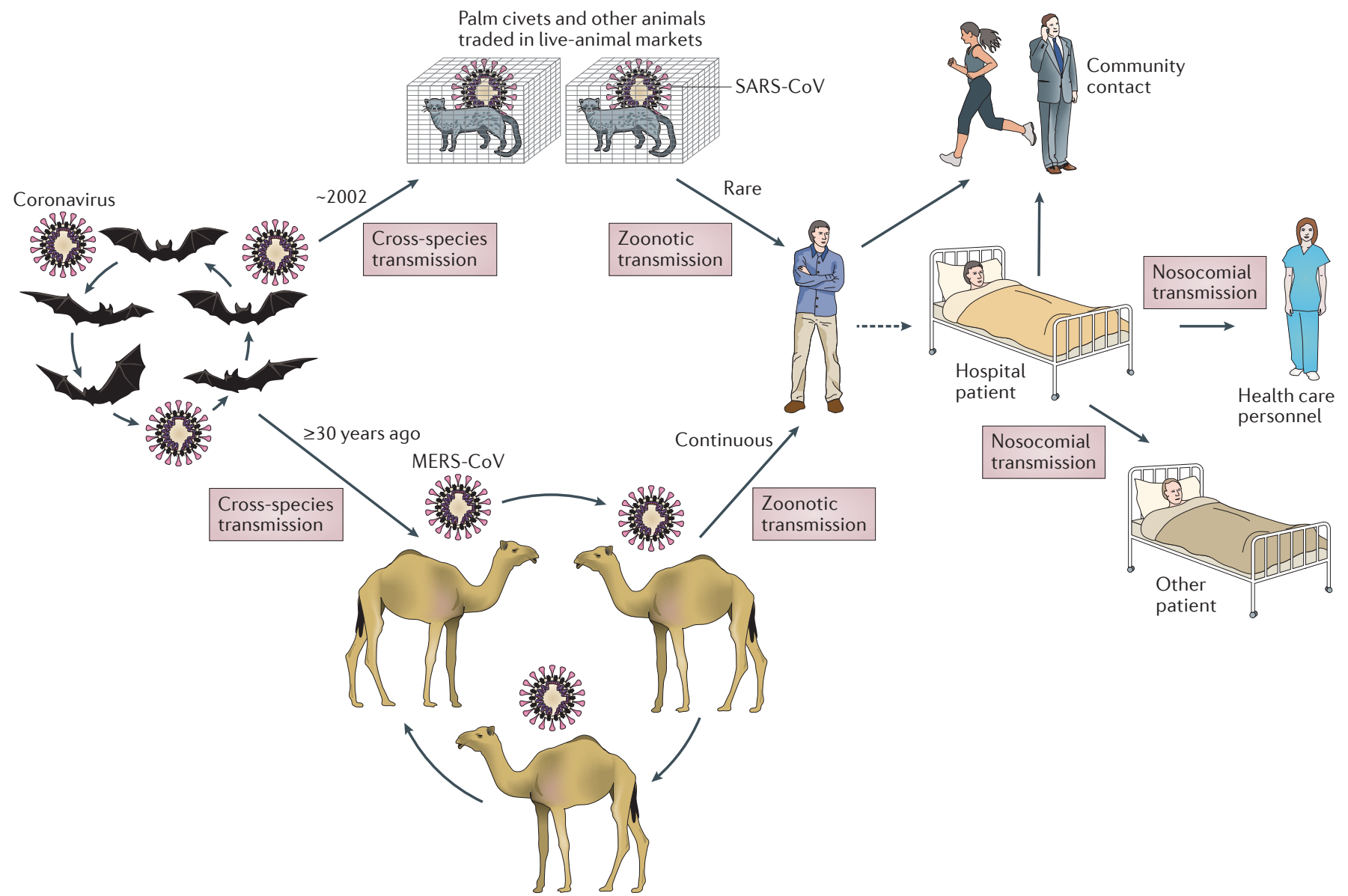

Figure 2 | The emergence of SARS-CoV and MERS-CoV. Bats harbour a wide range of coronaviruses, including severe acute respiratory syndrome coronavirus (SARS-CoV)-like and Middle East respiratory syndrome coronavirus (MERS-CoV)-like viruses. SARS-CoV crossed the species barrier into masked palm civets and other animals in live-animal markets in China; genetic analysis suggests that this occurred in late 2002. Several people in close proximity to palm civets became infected with SARS-CoV. A MERS-CoV ancestral virus crossed the species barrier into dromedary camels; serological evidence suggests that this happened more than 30 years ago. Abundant circulation of MERS-CoV in dromedary camels results in frequent zoonotic transmission of this virus. SARS-CoV and MERS-CoV spread between humans mainly through nosocomial transmission, which results in the infection of health care workers and patients at a higher frequency than infection of their relatives.

Acute respiratory distress syndrome (ARDS). A life-threatening condition in which the accumulation of fluid and inflammatory cells in the lungs decreases the exchange of oxygen and carbon dioxide to dangerously low levels.

Collaborative Cross mouse One of a panel of recombinant inbred mouse strains derived from a genetically diverse set of founder strains and designed for the analysis of complex traits.

Perivascular cuffing The aggregation of leukocytes around blood vessels.
(AGTR1A) increases pulmonary vascular permeability, thus potentially explaining the increased lung pathology when the expression of ACE2 is decreased ${ }^{46}$.

Immunopathology. The immune response is essential for the resolution of an infection, but it can also result in immunopathogenesis. One indication that immunopathogenesis may contribute to SARS was the observation that viral loads were found to be decreasing while disease severity increased ${ }^{39,47}$. It is unclear whether a similar trend applies to MERS ${ }^{48,49}$. Moreover, progression to acute respiratory distress syndrome (ARDS) is associated with the upregulation of pro-inflammatory cytokines and chemokines, particularly interleukin-1 $\beta$ (IL-1 $\beta$ ), IL-8, IL-6, CXC-chemokine ligand 10 (CXCL10) and CC-chemokine ligand 2 (CCL2) $)^{50,51}$; increased plasma levels of these molecules have been detected in patients with SARS ${ }^{52-55}$. Retrospective longitudinal studies in patients who recovered from SARS versus those who succumbed to the disease have shown an early expression of interferon- $\alpha$ (IFN $\alpha)$, IFN $\gamma$, CXCL10, CCL 2 and proteins that are encoded by IFN-stimulated genes (ISGs) in all patients, but only patients who survived then had gene expression profiles that are indicative of the development of an adaptive immune response. By contrast, patients who succumbed maintained high levels of CXCL10, CCL2 and ISG-encoded proteins, whereas spike-specific antibodies were present at low levels or were absent ${ }^{56}$, which suggests that severe disease is related to the lack of a switch from an innate immune response to an adaptive immune response.

Experiments using Collaborative Cross mouse lines and mouse-adapted SARS-CoV identified one host gene, Trim55, as important for SARS pathogenesis. Although there was no difference in clinical signs or viral replication in Trim55 $5^{-/-}$mice compared with wild-type mice, perivascular cuffing and the number of inflammatory cells in the lungs were reduced in the Trim $55^{-/-}$mice ${ }^{57}$. 


\section{Box 1 | Clinical features of SARS and MERS}

Severe acute respiratory syndrome coronavirus (SARS-CoV) and Middle East respiratory syndrome coronavirus (MERS-CoV) have an incubation period of $\sim 5$ days, and $95 \%$ of patients develop disease within 13 days of exposure ${ }^{14,38,144-146}$. Common early symptoms are fever, chills, coughing, malaise, myalgia and headache, and less common symptoms include diarrhoea, vomiting and nausea $2,6,39,89,90,92,95,144,146-148$. Upper respiratory tract symptoms and viral shedding are rare, which explains difficulties in obtaining a laboratory diagnosis from nasal or nasopharyngeal swabs ${ }^{149}$. Abnormal chest X-rays are more common in patients with MERS $(90-100 \%)^{144,148}$ than in those with SARS $(60-100 \%)^{39,89}$. Accordingly, only $20-30 \%$ of patients with SARS require intensive care and subsequent mechanical ventilation, whereas $50-89 \%$ of patients with MERS require intensive care $2,39,89,90,95,144,147,148$. The higher incidence of acute respiratory distress syndrome (ARDS) in individuals with MERS is reflected in the case fatality rate: this is $\sim 36 \%$ for MERS compared with $\sim 10 \%$ for SARS ${ }^{15,145}$.

Comorbidities have an important role in both SARS and MERS. Several risk factors are associated with poor disease outcome, especially advanced age and male sex $2,14,39,144,146,148,150,151$. For MERS, additional risk factors for a poor outcome include diabetes mellitus, hypertension, cancer, renal and lung disease, and co-infections ${ }^{14,144,146,148,150,151}$.

Health care settings seem to increase the risk of viral transmission owing to aerosol-generating procedures such as intubation and bronchoscopy. Appropriate hospital hygiene practices and awareness are crucial to limit future nosocomial outbreaks.

\section{Type I IFNs}

(Type I interferons). A group of IFNs, including IFNa and IFN $\beta$, with immune-modulating and antiviral functions.

\section{RNAi}

A biological process in which small RNA molecules induce the degradation of specific mRNA molecules, thereby inhibiting gene expression

Minireplicon systems Systems in which a DNA molecule is produced that contains the viral leader and trailer sequences, with an assayable reporter replacing the viral ORFs. When combined with the expression of viral proteins in trans, this system can be used to model the viral life cycle without the necessity of using infectious virus.
The involvement of the host immune response in the pathogenesis of SARS, and most likely also that of MERS, suggests that drugs which inhibit viral replication will need to be combined with treatments that control detrimental immune responses.

Immune evasion. SARS-CoV and MERS-CoV use several strategies to avoid the innate immune response. Viral pathogen-associated molecular patterns (PAMPs), such as double-stranded RNA (dsRNA) or uncapped mRNA, are detected by pattern recognition receptors (PRRs), such as retinoic acid-inducible gene I protein (RIG-I; also known as DDX58) or melanoma differentiation-associated protein 5 (MDA5; also known as IFIH1 $)^{58}$. This triggers complex signalling cascades involving MYD88 that lead to the production of type I IFNs and the activation of the transcription factor nuclear factor- $\kappa \mathrm{B}(\mathrm{NF}-\kappa \mathrm{B})$. In turn, active NF- $\kappa \mathrm{B}$ induces the transcription of pro-inflammatory cytokines (FIG. 3a). Type I IFNs signal through IFN $\alpha / \beta$ receptor (IFNAR) and downstream molecules such as signal transducer and activator of transcription (STAT) proteins to stimulate the production of antiviral proteins that are encoded by ISGs, such as IFN-induced protein with tetratricopeptide repeats 1 (IFIT1; FIG. 3b). Collectively, this establishes an antiviral immune response that limits viral replication in infected and in neighbouring cells (FIG. 3).

Infection of knockout mice revealed the importance of innate immunity. Infection of $\mathrm{Myd} 88^{-/-}$and Stat $1^{-/-}$ mice, but not mice that were deficient in IFN receptors, with a mouse-adapted strain of SARS-CoV resulted in more severe disease than infection with a non-adapted SARS-CoV strain ${ }^{59,60}$. Moreover, MERS-CoV infection of wild-type mice that were transduced with human DPP4 caused mild disease, but symptoms were more severe in $M y d 88^{-/-}$mice and Ifnar $1^{-1-}$ mice $^{61}$.
SARS-CoV and MERS-CoV avoid host detection of their dsRNA by replicating in virus-induced doublemembrane vesicles that lack PRRs ${ }^{19,62,63}$. Moreover, the recognition of SARS-CoV mRNAs, for example, by MDA5 and IFIT1 is prevented by capping of the viral mRNAs by nsp14 and the nsp10-nsp16 complex ${ }^{64}$. Recombinant SARS-CoV that lacks the methylation activity of nsp16 is attenuated and exhibits increased sensitivity to type I IFNs. This effect is dependent on IFIT1 or MDA5, as the same virus is not attenuated in mice that are deficient in either molecule ${ }^{65}$. Although mRNA capping has not yet been shown for MERS$\mathrm{CoV}$, structural similarity between the MERS-CoV nsp10-nsp16 complex and the SARS-CoV nsp10-nsp16 complex suggests that a similar mechanism exists to avoid host recognition of MERS-CoV mRNAs by cytosolic PRRs ${ }^{66}$.

SARS-CoV encodes at least eight proteins that interact with the signalling cascades downstream of PRRs; in MERS-CoV, several proteins have been identified with similar functions (FIG. 3). The nucleocapsid protein of SARS-CoV has been associated with the suppression of RNAi in mammalian cells ${ }^{67}$. Furthermore, this protein antagonizes IFN induction, probably early in the signalling cascade, as downstream signalling molecules relieve the inhibition ${ }^{68}$. MERS-CoV ORF4a has a similar IFN-antagonistic function, involving the binding of dsRNA and subsequent inhibition of MDA5 activation ${ }^{69}$, potentially through interaction with IFN-inducible dsRNA-dependent protein kinase activator A (PRKRA; also known as PACT), which interacts with MDA5 and RIG-I ${ }^{70}$. Moreover, MERS-CoV ORF4a, ORF4b, ORF5 and membrane protein inhibit the nuclear trafficking of IFN-regulatory factor 3 (IRF3) and activation of the IFNB promoter ${ }^{71}$. These viral proteins, except for ORF5, also inhibit the expression of genes that are under the control of an IFN-stimulated response element (ISRE), and ORF4a reduces the expression of genes that are stimulated by NF- $\kappa B^{71}$. Finally, MERS-CoV ORF4b interacts with TBK1 and inhibitor of NF- $\kappa$ B kinase- $\varepsilon$ (IKKe), thereby suppressing the interaction between IKKe and mitochondrial antiviral-signalling protein (MAVS) and inhibiting the phosphorylation of IRF3 (REF. 72).

The membrane protein of SARS-CoV inhibits the formation of a signalling complex that contains IKKe, thus repressing the activation of IRF3 and IRF7 and their induction of type I IFN expression. The membrane protein of MERS-CoV inhibits IRF3 function and the expression of genes that are regulated by an ISRE, including IFN $\beta^{71}$, but whether this occurs through a mechanism similar to that of SARS-CoV is unclear.

SARS-CoV PLpro disrupts NF- $\kappa B$ signalling ${ }^{73}$ and blocks the phosphorylation of IRF3 indirectly ${ }^{73,74}$. Furthermore, SARS-CoV PLpro inhibits the induction of type I IFNs, potentially through the deubiquitylation of phosphorylated IRF3 (REFS 73,75). Similar functions have been described for MERS-CoV PLpro ${ }^{76}$.

Experiments involving recombinantly expressed proteins, in vitro translation, protein overexpression and minireplicon systems have shown that nsp1 of SARSCoV blocks the IFN response through the inhibition of 

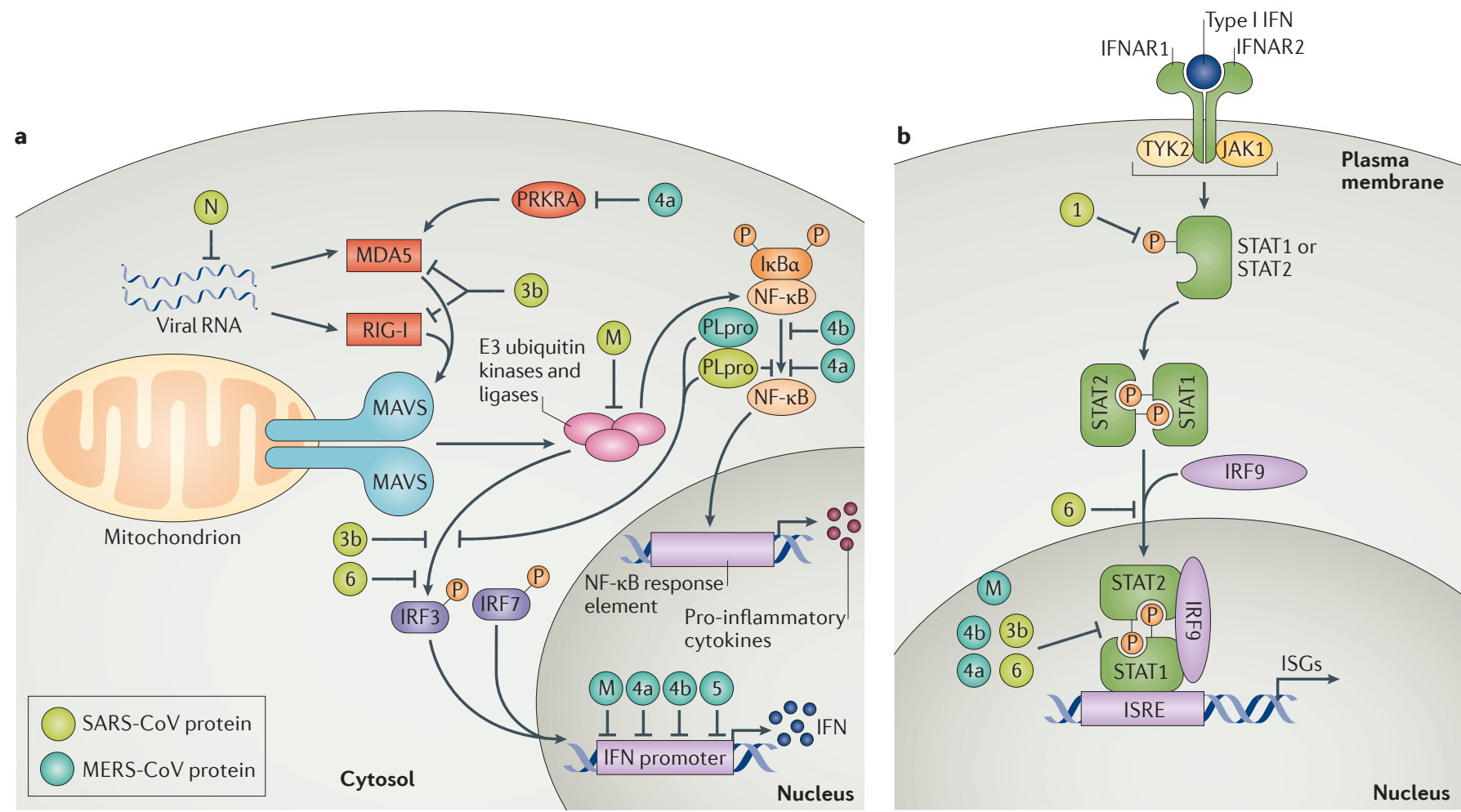

Figure 3 | Evasion of the innate immune response by SARS-CoV and MERS-CoV. a | The innate immune response is activated by the detection of viral pathogen-associated molecular patterns (PAMPs), such as double-stranded RNA (dsRNA) or uncapped mRNA. This occurs via host pattern recognition receptors (PRRs), such as retinoic acid-inducible gene I protein (RIG-I) and melanoma differentiation-associated protein 5 (MDA5), potentially via dsRNA-binding partners such as IFN-inducible dsRNA-dependent protein kinase activator A (PRKRA). Following PRR-mediated detection of a PAMP, the resulting interaction of PRRs with mitochondrial antiviral-signalling protein (MAVS) activates nuclear factor- $\mathrm{kB}(\mathrm{NF}-\kappa \mathrm{B})$ through a signalling cascade involving several kinases. Activated NF- $\mathrm{kB}$ translocates to the nucleus, where it induces the transcription of pro-inflammatory cytokines. The kinases also phosphorylate (P) IFN-regulatory factor 3 (IRF3) and IRF7, which form homodimers and heterodimers and enter the nucleus to initiate the transcription of type I interferons (type I IFNs). Both severe acute respiratory syndrome coronavirus (SARS-CoV) and Middle East respiratory syndrome coronavirus (MERS-CoV) have developed mechanisms to interfere with these signalling pathways, as shown; these subversion strategies involve both structural proteins (membrane (M) and nucleocapsid (N)) and non-structural proteins (nsp1, nsp3b, nsp4a, nsp4b, nsp5, nsp6 and papain-like protease (PLpro); indicated in the figure by just their nsp numbers and letters). $\mathbf{b}$ | Binding of type I IFNs to their dimeric receptor, IFNa/ $\beta$ receptor (IFNAR), activates the Janus kinase (JAK)-signal transducer and activator of transcription (STAT) signalling pathway, in which JAK1 and TYK2 kinases phosphorylate STAT1 and STAT2, which form complexes with IRF9. These complexes move into the nucleus to initiate the transcription of IFN-stimulated genes (ISGs) under the control of promoters that contain an IFN-stimulated response element (ISRE). Collectively, the expression of cytokines, IFNs and ISGs establishes an antiviral innate immune response that limits viral replication in infected and in neighbouring cells. Again, viral proteins have been shown to inhibit these host signalling pathways to evade this immune response.

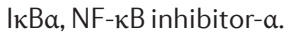

STAT1, degradation of host mRNAs and inactivation of the host translational machinery through a tight association with the $40 \mathrm{~S}$ ribosomal subunit ${ }^{77-80}$. Nsp1 of MERS-CoV also inhibits the translation of mRNAs and induces mRNA degradation, although the translational inhibition is achieved through a different mechanism than ribosome binding, which selectively targets the translation of nuclear mRNAs and thereby spares cytoplasmic viral mRNAs ${ }^{81}$.

SARS-CoV ORF3b inhibits the production of type I IFN, the phosphorylation of IRF3 and gene expression from an ISRE promoter ${ }^{82,83}$. SARS-CoV ORF6 also blocks the nuclear translocation of STAT1 (REF. 83).
Both nsp7 and nsp15 from SARS-CoV were also suggested to be IFN antagonists, but the underlying mechanism is unknown ${ }^{73}$. nsp15 is an inhibitor of MAVSinduced apoptosis; however, this occurs through an IFN-independent mechanism ${ }^{84}$. Finally, transcriptomic and proteomic analysis of human airway cell cultures showed that MERS-CoV but not SARS-CoV induces repressive histone modifications that downregulate the expression of certain ISGs ${ }^{85}$.

It should be noted that most of the interactions of SARS-CoV and MERS-CoV proteins with innate immune pathways were established in in vitro systems, which rely on the overexpression of viral and, 
Table 1 | Potential therapeutics for MERS

\begin{tabular}{|c|c|c|}
\hline Treatment & Stage of development & References \\
\hline Host protease inhibitors & In vitro inhibition & 132 \\
\hline Viral protease inhibitors & In vitro inhibition & $97,99,112-114$ \\
\hline $\begin{array}{l}\text { Repurposed FDA-approved } \\
\text { drugs }\end{array}$ & In vitro inhibition & $62,99,113,115$ \\
\hline $\begin{array}{l}\text { Monoclonal and polyclonal } \\
\text { antibodies }\end{array}$ & $\begin{array}{l}\text { Effective in mouse, rabbit and } \\
\text { non-human primate models }\end{array}$ & $\begin{array}{r}118-121 \\
123-128\end{array}$ \\
\hline Convalescent plasma & $\begin{array}{l}\text { Effective in a mouse model; clinical } \\
\text { trial approved }\end{array}$ & 122 \\
\hline Interferons & $\begin{array}{l}\text { Effective in non-human primate } \\
\text { models; off-label use in patients }\end{array}$ & $\begin{array}{r}87,97-99, \\
101-105,108-111\end{array}$ \\
\hline Ribavirin & $\begin{array}{l}\text { Effective in a non-human primate } \\
\text { model; off-label use in patients }\end{array}$ & $\begin{array}{r}87,88,101,102 \\
108-111\end{array}$ \\
\hline Mycophenolic acid & $\begin{array}{l}\text { Failed to protect in a non-human } \\
\text { primate model }\end{array}$ & $97,99,105,113$ \\
\hline Lopinavir and ritonavir & $\begin{array}{l}\text { Effective in a non-human primate } \\
\text { model; off-label use in patients }\end{array}$ & $105,109-111$ \\
\hline
\end{tabular}

MERS, Middle East respiratory syndrome.

sometimes, cellular proteins, and these interactions have rarely been confirmed in the context of viral replication in vitro or in vivo.

\section{Treatment of severe coronavirus infections}

Several strategies are being considered to treat infections with MERS-CoV (TABLE 1) and SARS-CoV, including the use of antibodies, IFNs, inhibitors of viral and host proteases, and host-directed therapies.

Current therapies. In the absence of a clinically proven effective antiviral therapy against SARS-CoV and MERS-CoV, patients mainly receive supportive care, which is often supplemented by different combinations of drugs. Ribavirin ${ }^{86}$ and various types of IFN have been given to patients with MERS in Saudi Arabia ${ }^{87}$ and China ${ }^{88}$, typically in combination with a broad-spectrum antibiotic and oxygen. The efficacy of treatments for SARS-CoV and MERS-CoV infection currently remains unclear. In addition, treatment for MERS is typically started only in a late disease stage, when immunopathology predominates and antiviral drugs are likely to provide little benefit.

Ribavirin was used most frequently during the SARS Ribavirin

A broadly active antiviral nucleoside analogue with several direct and indirect mechanisms of action; mainly used for the treatment of hepatitis $C$, in combination with interferon.

Pegylated

Having polyethylene glycol (PEG) attached, to a drug for example; this moiety improves the solubility, decreases the immunogenicity and increases the stability, of the drug of interest, thereby allowing a reduced dosing frequency to be used. underlying mechanism is unclear and is not related to the proofreading function of nsp14 (REF. 96). Therefore, ribavirin should be considered only in combination with other antiviral treatments.

Although IFNs are effective against MERS-CoV in vitro ${ }^{97-99}$, their effect in humans has yet to be proved. The effectiveness of IFN is increased in vitro if ribavirin is added ${ }^{98,100}$, and a combined use of the two drugs reduces disease severity in a rhesus macaque model of MERS $^{101}$. The potential side effects of these treatments, such as fatigue, depression and anaemia, have inhibited their use as a first-line treatment for MERS, and they are generally administered only after a patient's condition starts to deteriorate. For example, one study of five patients who were infected with MERS-CoV indicated no survival following ribavirin and IFNa2b therapy; however, therapy was not started until 10 days after admission $^{87}$. A separate study found an improvement in survival 14 days after MERS diagnosis and the start of treatment, but not 28 days after ${ }^{102}$. In a third study, a combination of IFNa2a and ribavirin or IFN $\beta 1 \mathrm{a}$ and ribavirin did not improve survival; however, some of the patients were more than 50 years old and had preexisting renal failure ${ }^{103}$. In a single case in which ribavirin and IFNa2b were started shortly after admission to hospital, the patient started to improve on day 6 after admission and made a complete recovery ${ }^{104}$.

IFN $\beta 1 b$ is a more potent inhibitor of MERS-CoV replication in vitro than other types of $\mathrm{IFN}^{97,99}$, and an improved outcome of disease was observed in common marmosets after challenge with MERS-CoV ${ }^{105}$. Thus, the type of IFN that is used for treatment in humans should be reconsidered (usually, IFNa is used). Furthermore, ribavirin and/or IFNs should be tested in clinical trials to determine their efficacy in MERS treatment and to establish treatment protocols.

Additional antiviral treatments. The protease inhibitors lopinavir and ritonavir, which are used in combination to treat infection with HIV, improved the outcome of patients with SARS when combined with ribavirin, compared with patients who were treated with ribavirin alone ${ }^{106,107}$. Lopinavir showed no clear antiviral activity against MERS-CoV in vitro ${ }^{97}$, and it is thus rarely used in patients with MERS. However, lopinavir and ritonavir improve the outcome in common marmosets when treatment is initiated 6 hours after infection with MERS$\mathrm{CoV}^{105}$. Thus, the testing of lopinavir and ritonavir in clinical trials in patients with MERS should be reconsidered. One patient who received pegylated IFNa, ribavirin, lopinavir and ritonavir in combination had undetectable levels of MERS-CoV in the blood 2 days after the initiation of therapy; however, this patient did not survive ${ }^{108}$. The combination of IFNa, ribavirin, lopinavir and ritonavir was also used for MERS treatment in South Korea, but efficacy data are not yet available. However, three case reports indicate recovery in five out of seven patients who were treated with this combination ${ }^{109-111}$.

As 3CLpro and PLpro are essential for cleavage of the viral polyproteins and are distinct from cellular proteases, they are ideal drug targets, in particular PLpro, 
which is involved in both viral replication and IFN antagonism. Indeed, most antiviral drug-like molecules have been developed against 3CLpro and PLpro, which was aided by the rapid report of crystal structures of these proteases ${ }^{112}$.

PLpro was initially identified as a drugable target for SARS-CoV; recently, it has been noted that some of the compounds that target PLpro from SARS-CoV are also active against PLpro from MERS-CoV. For example, both 6-mercaptopurine and 6-thioguanine inhibit MERS-CoV and SARS-CoV in vitro ${ }^{113}$; however, the efficacy of these molecules has not yet been tested in vivo. Mycophenolic acid also inhibits the replication of MERS-CoV in vitro ${ }^{97,99}$ through the inhibition of PLpro $^{113}$, but it had no effect in marmosets ${ }^{105}$.

As new coronaviruses are likely to emerge from bats, protease inhibitors were designed against bat coronaviruses with the goal of developing a universal antiviral compound against emerging zoonotic coronaviruses. This approach yielded an inhibitor of Tylonycteris bat coronavirus HKU4 (HKU4-CoV), which is closely related to MERS-CoV ${ }^{11}$. This inhibitor, named SG85, indeed inhibits MERS-CoV replication in vitro ${ }^{112}$. Similarly, peptidomimetics that target and inhibit 3CLpro of MERS-CoV, HKU4-CoV and Pipistrellus bat coronavirus HKU5 (HKU5-CoV) have also been identified, but have not yet progressed beyond the in vitro stage ${ }^{114}$.

Several other drugs that were approved for use in humans were shown to inhibit the replication of MERS$\mathrm{CoV}$ in vitro, notably chloroquine, chlorpromazine, loperamide and cyclosporine $\mathrm{A}^{62,99,113,115}$, although their mechanisms of action are unknown, and the benefit of cyclosporine $\mathrm{A}$ in patients is debatable owing to the immunosuppressive effect of the drug. Although cyclophilin inhibitors that do not result in immunosuppression are available, their activity against MERS-CoV has not yet been tested.

Antibody and plasma therapy. Plasma from convalescent patients and/or antibody therapies have been the leading proposed treatment for MERS so far ${ }^{116}$. There are several potential advantages to this approach. For example, as case numbers increase, the pool of survivors becomes larger; provided these individuals have sufficiently high antibody titres and are willing and able to donate plasma, this is a low-tech, reasonably safe treatment option. Furthermore, generation of monoclonal antibodies for use in humans is well established, with a fairly straightforward path to safety and efficacy testing. However, to date, there are very few reports on the use of convalescent plasma and none on the use of monoclonal antibodies as treatments for acute, severe respiratory disease in humans. A post hoc meta-analysis of 32 studies of either SARS or severe influenza found a significant reduction in the pooled odds of mortality when convalescent plasma was used ${ }^{117}$. However, study design was rated as low or very low quality, as there were generally a lack of control groups and a moderate-to-high risk of bias, which suggests that a properly designed clinical trial of convalescent plasma use in severe respiratory infections is needed ${ }^{117}$. Potent monoclonal antibodies that neutralize the MERS-COV spike protein in vitro have been developed ${ }^{118-121}$. However, with a few exceptions, in vivo data relating to the use of convalescent plasma or monoclonal antibodies in the treatment of MERS are currently lacking. Serum from high-titre dromedary camels decreased MERS-CoV loads in the lungs of mice that had been transduced with human DPP4 (REF. 122). Human polyclonal antibodies against the spike protein were generated by vaccinating transchromosomic bovines, and treatment with these antibodies reduced viral titres in the lungs of DPP4-transduced mice when treatment was administered 24 or 48 hours after challenge with MERS-CoV ${ }^{123}$. DPP4-transduced mice were also treated with humanized neutralizing monoclonal antibody $4 \mathrm{C} 2 \mathrm{~h}$, which is directed against the receptor-binding domain of the MERS-CoV spike protein, 1 day after MERS-CoV challenge, and this treatment also decreased viral titres in the lungs ${ }^{124}$, as did the neutralizing antibody LCA60, which was obtained from a convalescent patient and produced recombinantly ${ }^{125}$. Human neutralizing monoclonal antibodies REGN3048 and REGN3051 also provided a benefit in mice that expressed human DPP4 and were challenged with MERS-CoV ${ }^{126}$. The human neutralizing monoclonal antibody m332 reduced MERS-CoV replication in the lungs of rabbits following prophylactic, but not therapeutic, treatment ${ }^{127}$. Treatment of rhesus macaques with the human monoclonal antibody 311B-N1 day after challenge resulted in reduced lung pathology ${ }^{128}$. In all of these studies, viral replication was not completely inhibited, and there were some pathological alterations to the lungs, despite the therapy. Furthermore, none of the studies addressed the potential emergence of escape mutants in vivo.

Alternatively, antibodies that target the region of DPP4 that binds to the spike protein could be used to prevent entry of MERS-CoV; this approach was successful in vitro ${ }^{129}$. However, whether such a treatment would be feasible and would not have substantial adverse effects in humans remains to be determined.

Host-directed therapies. Host-directed strategies can also limit viral replication. For example, the spike protein of SARS-CoV is cleaved by cathepsin B and cathepsin L, transmembrane protease serine 2 (TMPRSS2) and possibly other host proteases ${ }^{130,131}$. Inhibition of host serine proteases by camostat reduced the entry of SARS-CoV and increased survival in a mouse model ${ }^{132}$. However, the targeting of host proteases is more likely to result in undesirable side effects than the targeting of viral proteases.

Another underappreciated strategy is attenuation of detrimental host responses. The development of such treatments would require a thorough understanding of the host responses that are involved in acute lung injury and ARDS, processes that are unfortunately poorly understood at the moment. Nonetheless, in vitro studies and limited studies in animal models with other respiratory viruses have shown that anaphylatoxin C5a is important for the development of acute lung injury, and blocking anaphylatoxin C5a can reduce lung pathology ${ }^{133}$. 
Subunit vaccines

Vaccines that contain immunogenic parts of a pathogen rather than the entire pathogen.

DNA vaccines

Vaccines based on the direct introduction of a plasmid encoding an antigen; following in situ production of this antigen, an immune response is mounted against it.

\section{Box 2 | Animal models}

Most of our understanding of the pathogenesis of severe acute respiratory syndrome (SARS) and Middle East respiratory syndrome (MERS) comes from animal studies. Ideally, these models recapitulate all or specific aspects of human disease. Several mouse models have been established, for example by using mouse-adapted SARS coronavirus (SARS-CoV) or expressing human receptors in mice ${ }^{152}$. Although it has been recognized that mice might poorly mimic specific human responses to infection, the availability of knockout and transgenic mice enables the targeted study of virus-host interactions. Several non-human primate models have been developed for SARS-CoV and MERS coronavirus (MERS-CoV) ${ }^{152}$. The close relationship of non-human primates to humans often allows faithful recapitulation of a disease and the host response. However, these benefits are countered by the need for specialized husbandry, the sometimes limited availability of the animals and reagents, and high costs.

The pathogenesis of SARS-CoV and MERS-CoV in their respective reservoir hosts is not nearly as well studied as that in humans. Currently, only one experimental-infection study has been carried out in bats with MERS-CoV${ }^{153}$, and none has been carried out for other coronaviruses. Thus, data are mostly limited to the detection of coronaviruses in naturally infected bats. The detection of coronaviruses mainly in faecal samples from bats and not in oral swabs suggests that replication in bats occurs predominantly in the gastrointestinal tract ${ }^{9,154,155}$. By contrast, a combination of intratracheal and intranasal inoculation of masked palm civets with SARS-CoV resulted in interstitial pneumonia, with oral and rectal viral shedding ${ }^{156}$.

The pathogenesis of MERS-CoV in dromedary camels has been studied experimentally in a limited number of animals. These animals developed transient mild disease; however, large quantities of MERS-CoV were shed from the upper respiratory tract, in line with the predominant replication of MERS-CoV in the nasal turbinates and larynx in these animals, which explains the frequent zoonotic transmission ${ }^{157}$. the full-length spike sequence reduced viral loads and pathology in the lungs after challenge with MERS-CoV 5 weeks after the last vaccination ${ }^{140}$.

One concern of vaccination in humans is vaccinemediated enhancement of disease, a process in which the disease following infection is more severe in vaccinated individuals than in unvaccinated individuals. Although this was observed in only a small subset of vaccine studies that were carried out for SARS-CoV ${ }^{136}$ and has not yet been observed in any of the published MERS-CoV vaccine studies, it is an important concern. Moreover, it is unclear who to vaccinate against MERS$\mathrm{CoV}$, as healthy individuals seem to be at little risk of severe disease. Older patients or patients with underlying disease, who have the highest risk of severe MERS, would be important target populations. However, vaccination in such patients can be problematic owing to their poor immune responses, as has been established for influenza virus ${ }^{141}$. In addition, vaccination of people with a high risk of exposure to MERS-CoV, such as health care workers, slaughterhouse workers and camel herders, is advisable ${ }^{142}$.

\section{Outlook}

As our understanding of the pathogenesis of emerging coronaviruses increases, so will the opportunities for the rational design of therapeutics that target viral replication or immunopathology. The rational design of new drugs and the repurposing of existing compounds have already resulted in the development of PLpro inhibitors and the identification of kinase inhibitors that inhibit the replication of SARS-CoV and MERS-CoV in vitro. However, only a few potential treatments have progressed past the identification of an effect in vitro, and in vivo studies to select the most promising treatment options are required. The development of several mouse models of MERS is thus an important step forward (BOX 2). Owing to the acute nature of MERS and the important role of immunopathology, combination therapies aimed at simultaneously inhibiting viral replication, limiting viral dissemination and dampening the host response are likely to yield the best results. Furthermore, treatment should be started as early as possible, rather than waiting until the patient has already developed extensive lung damage.

The development of therapies against SARS and MERS needs to focus on testing in humans, in properly controlled clinical trials. The current non-standardized, uncontrolled approach to treatment is not informative and may not be beneficial to the patient. The recent Ebola outbreak has demonstrated that rapid clinical trial design and approval are possible and that exceptional situations call for deviations from normal procedures (BOX 3).

While treatments are being developed and evaluated, the prevention of viral transmission is key to reducing the burden of MERS. The large proportion of nosocomial MERS-CoV infections indicates that preventive measures in hospitals are currently either not fully implemented or insufficient. Prevention of zoonotic transmission from dromedary camels is another possibility to decrease the number of MERS cases. The 


\section{Box 3 | Preparing for emerging viruses: lessons from SARS-CoV, MERS-CoV and Ebola virus}

When the severe acute respiratory syndrome (SARS) outbreak developed into the first pandemic of the twenty-first century, it became clear that the medical and scientific communities were not adequately prepared for the emergence of highly pathogenic viruses. Whereas several months elapsed and several thousand cases of SARS were observed before the causative agent was identified as SARS coronavirus (SARS-CoV) ${ }^{4-6}$, subsequent advances in molecular diagnostic tools, such as next generation sequencing, meant that Middle East respiratory syndrome coronavirus (MERS-CoV) was identified before it caused a large outbreak of MERS ${ }^{11}$. The availability of the full-length genome of MERS-CoV enabled the rapid development and distribution of diagnostic assays. The first animal models of disease, several treatment efficacy studies and the identification of the reservoir followed soon after. Unfortunately, the SARS pandemic did not yield solid clinical data on the efficacy of treatment regimens. These data are urgently needed for the treatment of MERS, as well as to prepare for novel coronaviruses that may emerge. Several studies have used synthetic biology to study the zoonotic transmission potential of SARS-CoV-like viruses from bats, $90,158,159$.

The Ebola virus outbreak in West Africa has highlighted the need for fast-tracking of potential treatments, as several clinical trials were started only towards the end of the outbreak. The combined experiences of the outbreaks of SARS, MERS and Ebola provide a blueprint for the response to emerging pathogens: after the identification of the causative agent, diagnostic assays need to be developed and distributed rapidly, and simultaneously, awareness of the new syndrome and reporting of (suspected) cases must be increased. In addition, infection control measures in health care facilities are essential. Research needs to focus on understanding the epidemiology, including pathogen transmission and identification of the reservoir and/or intermediate hosts. Animal models need to be developed, as well as therapeutic and prophylactic measures. Finally, promising treatments need to be fast-tracked into clinical trials.

first vaccines against MERS- $\mathrm{CoV}$ have been tested in dromedary camels ${ }^{140,143}$; indeed, when camels were vaccinated with a modified vaccinia virus that expresses the MERS-CoV spike protein, subsequent challenge of these animals with MERS-CoV resulted in less viral shedding than in unvaccinated animals ${ }^{143}$, thereby potentially limiting the transmission to naive animals or to humans. Certainly, there has been progress in the development of vaccines and therapies against emerging coronaviruses, but more research and rigorous testing is required if we are to successfully combat these novel pathogens.
1. Zhong, N. S. et al. Epidemiology and cause of severe acute respiratory syndrome (SARS) in Guangdong, People's Republic of China, in February, 2003. Lancet 362, 1353-1358 (2003).

2. Lee, N. et al. A major outbreak of severe acute respiratory syndrome in Hong Kong. N. Engl. J. Med. 348, 1986-1994 (2003).

3. Guan, Y. et al. Molecular epidemiology of the novel coronavirus that causes severe acute respiratory syndrome. Lancet 363, 99-104 (2004).

4. Drosten, C. et al. Identification of a novel coronavirus in patients with severe acute respiratory syndrome.

N. Engl. J. Med. 348, 1967-1976 (2003).

5. Ksiazek, T. G. et al. A novel coronavirus associated with severe acute respiratory syndrome N. Engl. J. Med. 348, 1953-1966 (2003).

6. Peiris, J. S. et al. Coronavirus as a possible cause of severe acute respiratory syndrome. Lancet 361 , 1319-1325 (2003).

7. WHO. Summary of probably SARS cases with onset of illness from 1 November 2002 to 31 July 2003. WHO, http://www.who.int/csr/sars/country/ table2004_04_21/en/ (2004).

8. Wang, M. et al. SARS-CoV infection in a restaurant from palm civet. Emerg. Infect. Dis. 11, 1860-1865 (2005).

9. Ge, X. Y. et al. Isolation and characterization of a bat SARS-like coronavirus that uses the ACE2 receptor. Nature 503, 535-538 (2013)

The isolation of a bat SARS-CoV-like virus that uses the human ACE2 as a receptor without prior adaptation, which suggests the potential for emergence without prior adaptation.

10. Menachery, V. D. et al. A SARS-like cluster of circulating bat coronaviruses shows potential for human emergence. Nat. Med. 21, 1508-1513 (2015) An assessment of the zoonotic potential of SARS-CoV-like viruses circulating in bats.

11. Zaki, A. M., van Boheemen, S., Bestebroer, T. M., Osterhaus, A. D. \& Fouchier, R. A. Isolation of a novel coronavirus from a man with pneumonia in Saudi Arabia. N. Engl. J. Med. 367, 1814-1820 (2012) The first identification of MERS-CoV as the cause of severe lower respiratory disease in humans.

12. Hijawi, B. et al. Novel coronavirus infections in Jordan, April 2012: epidemiological findings from a retrospective investigation. East. Mediterr. Health J. 19 (Suppl. 1), S12-S18 (2013).
13. Wise, J. Patient with new strain of coronavirus is treated in intensive care at London hospital. BMJ 345, e6455 (2012)

14. Korea Centers for Disease Control and Prevention Middle East respiratory syndrome coronavirus outbreak in the Republic of Korea, 2015. Osong Public Health Res. Perspect. 6, 269-278 (2015).

15. WHO. Coronavirus infections: disease outbreak news. WHO, http://www.who.int/csr/don/26-april-2016mers-saudi-arabia/en/ (2016)

16. Pasternak, A. O., Spaan, W. J. \& Snijder, E. J. Nidovirus transcription: how to make sense..? J. Gen. Virol. 87, 1403-1421 (2006).

17. Perlman, S. $\&$ Netland, J. Coronaviruses post-SARS: update on replication and pathogenesis. Nat. Rev. Microbiol. 7, 439-450 (2009).

18. Fehr, A. R. \& Perlman, S. Coronaviruses: an overview of their replication and pathogenesis. Methods $\mathrm{Mol}$. Biol. 1282, 1-23 (2015).

19. Knoops, K. et al. SARS-coronavirus replication is supported by a reticulovesicular network of modified endoplasmic reticulum. PLoS Biol. 6 , e226 (2008)

20. Snijder, E. J. et al. Unique and conserved features of genome and proteome of SARS-coronavirus, an early split-off from the coronavirus group 2 lineage. J. $\mathrm{Mol}$. Biol. 331, 991-1004 (2003).

21. Eckerle, L. D. et al. Infidelity of SARS-CoV nsp 14-exonuclease mutant virus replication is revealed by complete genome sequencing. PLoS Pathog. 6 , e1000896 (2010)

The finding that nsp 14 has a crucial role in the proofreading ability of SARS-CoV.

22. Sevajol, M., Subissi, L., Decroly, E., Canard, B. \& Imbert, I. Insights into RNA synthesis, capping, and proofreading mechanisms of SARS-coronavirus. Virus Res. 194, 90-99 (2014).

23. Raj, V. S. et al. Dipeptidyl peptidase 4 is a functional receptor for the emerging human coronavirus-EMC. Nature 495, 251-254 (2013).

The demonstration that DPP4 is the receptor for MERS-CoV.

24. Masters, P. S. \& Perlman, S. in Fields Virology (eds Knipe, D. M. \& Howley, P. M.) 825-858 (Wolters Kluwer, 2013)

25. Guan, Y. et al. Isolation and characterization of viruses related to the SARS coronavirus from animals in southern China. Science 302, 276-278 (2003).
26. Wang, L. F. et al. Review of bats and SARS Emerg. Infect. Dis. 12, 1834-1840 (2006).

27. Drexler, J. F., Corman, V. M. \& Drosten, C. Ecology, evolution and classification of bat coronaviruses in the aftermath of SARS. Antiviral Res. 101, 45-56 (2014).

28. Reusken, C. B. et al. Middle East respiratory syndrome coronavirus neutralizing serum antibodies in dromedary camels: a comparative serological study. Lancet Infect. Dis. 13, 859-866 (2013). The first of several papers to provide serological evidence for the circulation of MERS-CoV among dromedary camels; this finding eventually led to the identification of dromedary camels as the main reservoir for MERS-CoV.

29. Haagmans, B. L. et al. Middle East respiratory syndrome coronavirus in dromedary camels: an outbreak investigation. Lancet Infect. Dis. 14 140-145 (2014)

30. Azhar, E. l. et al. Evidence for camel-to-human transmission of MERS coronavirus. N. Engl. J. Med. 370, 2499-2505 (2014).

31. Hemida, M. G. et al. MERS coronavirus in dromedary camel herd, Saudi Arabia. Emerg. Infect. Dis. 20, 1231-1234 (2014)

32. Raj, V. S. et al. Isolation of MERS coronavirus from a dromedary camel, Qatar, 2014. Emerg. Infect. Dis. 20, 1339-1342 (2014)

33. Muller, M. A. et al. MERS coronavirus neutralizing antibodies in camels, Eastern Africa, 1983-1997. Emerg. Infect. Dis. 20, 2093-2095 (2014).

34. Sabir J. S et al. Co-circulation of three came coronavirus species and recombination of MERS-CoVs in Saudi Arabia. Science 351, 81-84 (2016).

35. Chowell, G. et al. Transmission characteristics of MERS and SARS in the healthcare setting: a comparative study. BMC Med. 13, 210 (2015).

An analysis of the predominant role for nosocomial transmission in the epidemiology of both SARS and MERS.

36. Hunter, J. C et al. Transmission of Middle East respiratory syndrome coronavirus infections in healthcare settings, Abu Dhabi. Emerg. Infect. Dis. 22, 647-656 (2016).

37. Anderson, R. M. et al. Epidemiology, transmission dynamics and control of SARS: the 2002-2003 epidemic. Philos. Trans. R. Soc. Lond. B. Biol. Sci. 359 1091-1105 (2004) 
38. Cowling, B. J. et al. Preliminary epidemiological assessment of MERS-CoV outbreak in South Korea, May to June 2015. Euro Surveill. 20, 7-13 (2015)

39. Peiris, J. S. et al. Clinical progression and viral load in a community outbreak of coronavirus-associated SARS pneumonia: a prospective study. Lancet 361 1767-1772 (2003).

A description of the clinical representation of SARS-CoV respiratory disease in patients from Hong Kong.

40. Bin, S. Y. et al. Environmental contamination and viral shedding in MERS patients during MERS-CoV outbreak in South Korea. Clin. Infect. Dis. 62, 755-760 (2015)

Evidence that infectious MERS-CoV can be detected on common hospital surfaces during an outbreak, which highlights the potential for nosocomial transmission and stresses the need for infection control.

41. Kucharski, A. J. \& Althaus, C. L. The role of superspreading in Middle East respiratory syndrome coronavirus (MERS-CoV) transmission. Euro Surveill. 20, 14-18 (2015)

42. Oh, M. D. et al. Middle East respiratory syndrome coronavirus superspreading event involving 81 persons, Korea 2015. J. Korean Med. Sci. 30 , 1701-1705 (2015).

43. Wong, G. et al. MERS, SARS, and Ebola: the role of super-spreaders in infectious disease. Cell Host Microbe 18, 398-401 (2015)

44. Ng, D. L. et al. Clinicopathologic, immunohistochemical, and ultrastructural findings of a fatal case of Middle East respiratory syndrome coronavirus infection in the United Arab Emirates, April 2014. Am. J. Pathol. 186, 652-658 (2016).

45. Kuba, K. et al. A crucial role of angiotensin converting enzyme 2 (ACE2) in SARS coronavirus-induced lung injury. Nat. Med. 11, 875-879 (2005).

46. Imai, Y. et al. Angiotensin-converting enzyme 2 protects from severe acute lung failure. Nature $\mathbf{4 3 6}$, 112-116 (2005)

47. Wang, W. K. et al. Temporal relationship of viral load, ribavirin, interleukin (IL)-6, IL-8, and clinical progression in patients with severe acute respiratory syndrome. Clin. Infect. Dis. 39, 1071-1075 (2004).

48. Drosten, C. et al. Clinical features and virological analysis of a case of Middle East respiratory syndrome coronavirus infection. Lancet Infect. Dis. 13, 745-751 (2013).

49. Poissy, J. et al. Kinetics and pattern of viral excretion in biological specimens of two MERS-CoV cases. J. Clin. Virol. 61, 275-278 (2014).

50. Binnie, A., Tsang, J. L. \& dos Santos, C. C. Biomarkers in acute respiratory distress syndrome. Curr. Opin. Crit. Care 20, 47-55 (2014)

51. Williams, A. E. \& Chambers, R. C. The mercurial nature of neutrophils: still an enigma in ARDS? Am. J. Physiol. Lung Cell. Mol. Physiol. 306 L217-L230 (2014).

52. Baas, T., Taubenberger, J. K., Chong, P. Y., Chui, P. \& Katze, M. G. SARS-CoV virus-host interactions and comparative etiologies of acute respiratory distress syndrome as determined by transcriptional and cytokine profiling of formalin-fixed paraffin-embedded tissues. J. Interferon Cytokine Res. 26, 309-317 (2006).

53. Faure, E. et al. Distinct immune response in two MERS-CoV-infected patients: can we go from bench to bedside? PLOS ONE 9 e88716 (2014).

54. Kong, S. L., Chui, P., Lim, B. \& Salto-Tellez, M. Elucidating the molecular physiopathology of acute respiratory distress syndrome in severe acute respiratory syndrome patients. Virus Res. 145 260-269 (2009).

55. Tang, N. L. et al. Early enhanced expression of interferon-inducible protein-10 (CXCL-10) and other chemokines predicts adverse outcome in severe acute respiratory syndrome. Clin. Chem. 51, 2333-2340 (2005).

56. Cameron, M. J. et al. Interferon-mediated immunopathological events are associated with atypical innate and adaptive immune responses in patients with severe acute respiratory syndrome. J. Virol. 81, 8692-8706 (2007).

57. Gralinski, L. E. et al. Genome wide identification of SARS-CoV susceptibility loci using the Collaborative Cross. PLoS Genet. 11, e1005504 (2015).

58. Jensen, S. \& Thomsen, A. R. Sensing of RNA viruses: a review of innate immune receptors involved in recognizing RNA virus invasion. J. Virol. 86 2900-2910 (2012).
59. Frieman, M. B. et al. SARS-CoV pathogenesis is regulated by a STAT 1 dependent but a type I, II and III interferon receptor independent mechanism. PLOS Pathog. 6, e1000849 (2010).

60. Sheahan, T. et al. MyD88 is required for protection from lethal infection with a mouse-adapted SARS-CoV. PLoS Pathog. 4, e1000240 (2008).

61. Zhao, J. et al. Rapid generation of a mouse model for Middle East respiratory syndrome. Proc. Natl Acad. Sci. USA 111, 4970-4975 (2014).

A study in which the DPP4-based host restriction is overcome in mice by expression of the human variant of DPP4, leading to the development of several transgenic mouse models.

62. de Wilde, A. H. et al. MERS-coronavirus replication induces severe in vitro cytopathology and is strongly inhibited by cyclosporin A or interferon- $\alpha$ treatment. J. Gen. Virol. 94, 1749-1760 (2013).

63. Snijder, E. J. et al. Ultrastructure and origin of membrane vesicles associated with the severe acute respiratory syndrome coronavirus replication complex. J. Virol. 80, 5927-5940 (2006).

64. Bouvet, M. et al. In vitro reconstitution of SARS-coronavirus mRNA cap methylation. PLoS Pathog. 6, e1000863 (2010).

65. Menachery, V. D. et al. Attenuation and restoration of severe acute respiratory syndrome coronavirus mutant lacking 2'-O-methyltransferase activity. J. Virol. 88, 4251-4264 (2014).

66. Menachery, V. D., Debbink, K. \& Baric, R. S. Coronavirus non-structural protein 16: evasion, attenuation, and possible treatments. Virus Res. 194, 191-199 (2014).

67. Cui, L. et al. The nucleocapsid protein of coronaviruses acts as a viral suppressor of RNA silencing in mammalian cells. J. Virol. 89, 9029-9043 (2015).

68. Lu, X., Pan, J., Tao, J. \& Guo, D. SARS-CoV nucleocapsid protein antagonizes IFN- $\beta$ response by targeting initial step of IFN- $\beta$ induction pathway, and its C-terminal region is critical for the antagonism. Virus Genes 42, 37-45 (2011)

69. Niemeyer, D. et al. Middle East respiratory syndrome coronavirus accessory protein $4 \mathrm{a}$ is a type I interferon antagonist. J. Virol. 87, 12489-12495 (2013).

70. Siu, K. L. et al. Middle east respiratory syndrome coronavirus 4 a protein is a double-stranded RNA-binding protein that suppresses PACT-induced activation of RIG-I and MDA5 in the innate antiviral response. J. Virol. 88, 4866-4876 (2014).

71. Yang, Y. et al. The structural and accessory proteins M, ORF 4a, ORF 4b, and ORF 5 of Middle East respiratory syndrome coronavirus (MERS-CoV) are potent interferon antagonists. Protein Cell $\mathbf{4}$ 951-961 (2013)

72. Yang, Y et al. Middle East respiratory syndrome coronavirus ORF4b protein inhibits type I interferon production through both cytoplasmic and nuclear targets. Sci. Rep. 5, 17554 (2015).

73. Frieman, M., Ratia, K., Johnston, R. E., Mesecar, A. D. \& Baric, R. S. Severe acute respiratory syndrome coronavirus papain-like protease ubiquitin-like domain and catalytic domain regulate antagonism of IRF3 and NF-кB signaling. J. Virol. 83, 6689-6705 (2009).

74. Devaraj, S. G. et al. Regulation of IRF-3-dependent innate immunity by the papain-like protease domain of the severe acute respiratory syndrome coronavirus. J. Biol. Chem. 282, 32208-32221 (2007).

75. Matthews, K., Schafer, A., Pham, A. \& Frieman, M. The SARS coronavirus papain like protease can inhibit IRF3 at a post activation step that requires deubiquitination activity. Virol. J. 11, 209 (2014).

76. Bailey-Elkin, B. A. et al. Crystal structure of the Middle East respiratory syndrome coronavirus (MERS-CoV) papain-like protease bound to ubiquitin facilitates targeted disruption of deubiquitinating activity to demonstrate its role in innate immune suppression. J. Biol. Chem. 289, 34667-34682 (2014)

77. Huang, C. et al. SARS coronavirus nsp 1 protein induces template-dependent endonucleolytic cleavage of mRNAs: viral mRNAs are resistant to nsp 1 -induced RNA cleavage. PLoS Pathog. 7, e1002433 (2011).

78. Kamitani, W., Huang, C., Narayanan, K. Lokugamage, K. G. \& Makino, S. A two-pronged strategy to suppress host protein synthesis by SARS coronavirus nsp 1 protein. Nat. Struct. Mol. Biol. 16, 1134-1140 (2009)

79. Tanaka, T., Kamitani, W., DeDiego, M. L., Enjuanes, L. \& Matsuura, Y. Severe acute respiratory syndrome coronavirus nsp 1 facilitates efficient propagation in cells through a specific translational shutoff of host mRNA. J. Virol. 86, 11128-11137 (2012).
80. Wathelet, M. G., Orr, M., Frieman, M. B. \& Baric, R. S Severe acute respiratory syndrome coronavirus evades antiviral signaling: role of nsp 1 and rational design of an attenuated strain. J. Virol. 81, 11620-11633 (2007).

81. Lokugamage, K. G. et al. Middle East respiratory syndrome coronavirus nsp 1 inhibits host gene expression by selectively targeting mRNAs transcribed in the nucleus while sparing mRNAs of cytoplasmic origin. J. Virol. 89, 10970-10981 (2015).

82. Freundt, E. C., Yu, L., Park, E., Lenardo, M. J. \& $\mathrm{Xu}, \mathrm{X}$. N. Molecular determinants for subcellular localization of the severe acute respiratory syndrome coronavirus open reading frame $3 \mathrm{~b}$ protein. J. Virol. 83, 6631-6640 (2009)

83. Kopecky-Bromberg, S. A., Martinez-Sobrido, L. Frieman, M., Baric, R. A. \& Palese, P. Severe acute respiratory syndrome coronavirus open reading frame (ORF) 3b, ORF 6, and nucleocapsid proteins function as interferon antagonists. J. Virol. 81, 548-557 (2007).

84. Lei, Y. et al. MAVS-mediated apoptosis and its inhibition by viral proteins. PLOS ONE 4, e5466 (2009).

85. Menachery, V. D. et al. Pathogenic influenza viruses and coronaviruses utilize similar and contrasting approaches to control interferon-stimulated gene responses. mBio 5, e01174-14 (2014).

86. Graci, J. D. \& Cameron, C. E. Mechanisms of action of ribavirin against distinct viruses. Rev. Med. Virol. 16, 37-48 (2006)

87. Al-Tawfiq, J. A., Momattin, H., Dib, J. \& Memish, Z. A Ribavirin and interferon therapy in patients infected with the Middle East respiratory syndrome coronavirus: an observational study. Int. J. Infect. Dis. 20, 42-46 (2014)

88. Ling, Y., Qu, R. \& Luo, Y. Clinical analysis of the first patient with imported Middle East respiratory syndrome in China. Zhonghua Wei Zhong Bing Ji Jiu Yi Xue 27, 630-634 (in Chinese) (2015).

89. Booth, C. M. et al. Clinical features and short-term outcomes of 144 patients with SARS in the greater Toronto area. JAMA 289, 2801-2809 (2003).

90. Poutanen, S. M. et al. Identification of severe acute respiratory syndrome in Canada. N. Engl. J. Med. 348, 1995-2005 (2003)

91. So, L. K. et al. Development of a standard treatment protocol for severe acute respiratory syndrome. Lancet 361, 1615-1617 (2003).

92. Tsang, K. W. et al. A cluster of cases of severe acute respiratory syndrome in Hong Kong. N. Engl. J. Med. 348, 1977-1985 (2003)

93. Loutfy, M. R. et al. Interferon alfacon-1 plus corticosteroids in severe acute respiratory syndrome: a preliminary study. JAMA 290, 3222-3228 (2003)

94. Zhao, Z. et al. Description and clinical treatment of an early outbreak of severe acute respiratory syndrome (SARS) in Guangzhou, PR China. J. Med. Microbiol. 52, 715-720 (2003)

95. Hsu, L. Y. et al. Severe acute respiratory syndrome (SARS) in Singapore: clinical features of index patient and initial contacts. Emerg. Infect. Dis. 9, 713-717 (2003).

96. Smith, E. C., Blanc, H., Surdel, M. C., Vignuzzi, M. \& Denison, M. R. Coronaviruses lacking exoribonuclease activity are susceptible to lethal mutagenesis: evidence for proofreading and potential therapeutics. PLoS Pathog. 9, e 1003565 (2013).

97. Chan, J. F. et al. Broad-spectrum antivirals for the emerging Middle East respiratory syndrome coronavirus. J. Infect. 67, 606-616 (2013).

98. Falzarano, D. et al. Inhibition of novel $\beta$ coronavirus replication by a combination of interferon- $\alpha 2 b$ and ribavirin. Sci. Rep. 3, 1686 (2013)

99. Hart, B. J. et al. Interferon- $\beta$ and mycophenolic acid are potent inhibitors of Middle East respiratory syndrome coronavirus in cell-based assays. J. Gen. Virol. 95, 571-577 (2014).

100. Morgenstern, B., Michaelis, M., Baer, P. C. Doerr, H. W. $\&$ Cinatl, J. Ribavirin and interferon- $\beta$ synergistically inhibit SARS-associated coronavirus replication in animal and human cell lines. Biochem Biophys. Res. Commun. 326, 905-908 (2005)

101. Falzarano, D. et al. Treatment with interferon- $\alpha 2 b$ and ribavirin improves outcome in MERS-CoV-infected rhesus macaques. Nat. Med. 19, 1313-1317 (2013). The first application of a potential treatment option for MERS through the repurposing of IFNa2b and ribavirin in a non-human primate model.

102. Omrani, A. S. et al. Ribavirin and interferon alfa-2a for severe Middle East respiratory syndrome coronavirus infection: a retrospective cohort study. Lancet Infect. Dis. 14, 1090-1095 (2014). 
103. Shalhoub, S. et al. IFN- $\alpha 2$ a or IFN- $\beta 1$ a in combination with ribavirin to treat Middle East respiratory syndrome coronavirus pneumonia: a retrospective study. J. Antimicrob. Chemother. 70, 2129-2132 (2015).

104. Khalid, M. et al. Ribavirin and interferon- $a 2 b$ as primary and preventive treatment for Middle East respiratory syndrome coronavirus: a preliminary report of two cases. Antivir. Ther. 20, 87-91 (2015).

105. Chan, J. F. et al. Treatment with lopinavir/ritonavir or interferon- $\beta 1 \mathrm{~b}$ improves outcome of MERS-CoV infection in a non-human primate model of common marmoset. J. Infect. Dis. 212, 1904-1913 (2015).

106. Chan, K. S. et al. Treatment of severe acute respiratory syndrome with lopinavir/ritonavir: a multicentre retrospective matched cohort study. Hong Kong Med. J. 9, 399-406 (2003).

107. Chu, C. M. et al. Role of lopinavir/ritonavir in the treatment of SARS: initial virological and clinical findings. Thorax 59, 252-256 (2004).

108. Spanakis, N. et al. Virological and serological analysis of a recent Middle East respiratory syndrome coronavirus infection case on a triple combination antiviral regimen. Int. J. Antimicrob. Agents 44, 528-532 (2014).

109. Choi, W. J., Lee, K. N., Kang, E. J. \& Lee, H Middle East respiratory syndrome-coronavirus infection: a case report of serial computed tomographic findings in a young male patient. Korean J. Radiol 17, 166-170 (2016).

110. Kim, U. J., Won, E. J., Kee, S. J., Jung, S. I. \& Jang, H. C. Combination therapy with lopinavir/ ritonavir, ribavirin and interferon-a for Middle East respiratory syndrome: a case report. Antivir. Ther http://dx.doi.org/10.3851/IMP3002 (2015).

111. Rhee, J. Y., Hong, G. \& Ryu, K. M. Clinical implications of five cases of Middle East respiratory syndrome coronavirus infection in South Korea Outbreak. Jpn J. Infect. Dis. http://dx.doi.org/10.7883/yoken. JJID. 2015.445 (2016)

112. Hilgenfeld, R. From SARS to MERS: crystallographic studies on coronaviral proteases enable antiviral drug design. FEBS J. 281, 4085-4096 (2014).

113. Cheng, K. W. et al. Thiopurine analogs and mycophenolic acid synergistically inhibit the papain like protease of Middle East respiratory syndrome coronavirus. Antiviral Res. 115, 9-16 (2015).

114. Tomar, S. et al. Ligand-induced dimerization of Middle East respiratory syndrome (MERS) coronavirus nsp5 protease ( $\left.3 \mathrm{CL}^{\text {pro }}\right)$ : implications for $n s p 5$ regulation and the development of antivirals. J. Biol. Chem. 290, 19403-19422 (2015)

115. de Wilde, A. H. et al. Screening of an FDA-approved compound library identifies four small-molecule inhibitors of Middle East respiratory syndrome coronavirus replication in cell culture. Antimicrob. Agents Chemother. 58, 4875-4884 (2014).

116. International Severe Acute Respiratory \& Emerging Infection Consortium. Treatment of MERS-CoV: decision support tool. International Severe Acute Respiratory \& Emerging Infection Consortium, https:// isaric.tghn.org/site_media/media/articles/Decision Support_Document_v1_1_20130729.pdf (updated 29 July 2013)

117. Mair-Jenkins, J. et al. The effectiveness of convalescent plasma and hyperimmune immunoglobulin for the treatment of severe acute respiratory infections of viral etiology: a systematic review and exploratory meta-analysis. J. Infect. Dis. 211, 80-90 (2015)

118. Du, L. et al. A conformation-dependent neutralizing monoclonal antibody specifically targeting receptorbinding domain in Middle East respiratory syndrome coronavirus spike protein. J. Virol. 88, 7045-7053 (2014).

119. Jiang, L. et al. Potent neutralization of MERS-CoV by human neutralizing monoclonal antibodies to the viral spike glycoprotein. Sci. Transl Med. 6, 234 ra59 (2014).

120. Tang, X. C. et al. Identification of human neutralizing antibodies against MERS-CoV and their role in virus adaptive evolution. Proc. Natl Acad. Sci. USA 111, E2018-E2026 (2014).

121. Ying, T. et al. Exceptionally potent neutralization of Middle East respiratory syndrome coronavirus by human monoclonal antibodies. J. Virol. 88 , 7796-7805 (2014)

122. Zhao, J. et al. Passive immunotherapy with dromedary immune serum in an experimental animal model for Middle East respiratory syndrome coronavirus infection. J. Virol. 89, 6117-6120 (2015).

123. Luke, T. et al. Human polyclonal immunoglobulin G from transchromosomic bovines inhibits MERS-CoV in vivo. Sci. Transl Med. 8, 326ra21 (2016).

124. Li, Y. et al. A humanized neutralizing antibody against MERS-CoV targeting the receptor-binding domain of the spike protein. Cell Res. 25, 1237-1249 (2015)

125. Corti, D. et al. Prophylactic and postexposure efficacy of a potent human monoclonal antibody against MERS coronavirus. Proc. Natl Acad. Sci. USA 112 10473-10478 (2015)

126. Pascal, K. E. et al. Pre- and postexposure efficacy of fully human antibodies against Spike protein in a novel humanized mouse model of MERS-CoV infection. Proc. Natl Acad. Sci. USA 112, 8738-8743 (2015)

The first description of the prophylactic and therapeutic efficacy of monoclonal antibodies in a mouse model.

127. Houser, K. V. et al. Prophylaxis with a MERS-CoVspecific human monoclonal antibody protects rabbits from MERS-CoV infection. J. Infect. Dis. 213 1557-1561 (2016)

128. Johnson, R. F. et al. 3B11-N, a monoclonal antibody against MERS-CoV, reduces lung pathology in rhesus monkeys following intratracheal inoculation of MERS-CoV Jordan-n3/2012. Virology 490, 49-58 (2016)

129. Ohnuma, K. et al. Inhibition of Middle East respiratory syndrome coronavirus infection by anti-CD26 monoclonal antibody. J. Virol. 87, 13892-13899 (2013).

130. Elshabrawy, H. A. et al. Identification of a broad spectrum antiviral small molecule against severe acute respiratory syndrome coronavirus and Ebola, Hendra, and Nipah viruses by using a novel high-throughput screening assay. J. Virol. 88, 4353-4365 (2014).

131. Glowacka, I. et al. Evidence that TMPRSS2 activates the severe acute respiratory syndrome coronavirus spike protein for membrane fusion and reduces viral control by the humoral immune response. J. Virol. 85 4122-4134 (2011)

132. Zhou, Y. et al. Protease inhibitors targeting coronavirus and filovirus entry. Antiviral Res. 116 76-84 (2015).

133. Wang, R., Xiao, H., Guo, R., Li, Y. \& Shen, B. The role of $\mathrm{C} 5 \mathrm{a}$ in acute lung injury induced by highly pathogenic viral infections. Emerg. Microbes Infect. 4, e28 (2015)

134. Josset, L et al. Cell host response to infection with novel human coronavirus EMC predicts potential antivirals and important differences with SARS coronavirus. mBio 4, e00165-13 (2013)

135. Graham, R. L., Donaldson, E. F. \& Baric, R. S. A decade after SARS: strategies for controlling emerging coronaviruses. Nat. Rev. Microbiol. 11, 836-848 (2013).

136. Roper, R. L. \& Rehm, K. E. SARS vaccines: where are we? Expert Rev. Vaccines 8, 887-898 (2009).

137. Du, L. \& Jiang, S. Middle East respiratory syndrome: current status and future prospects for vaccine development. Expert Opin. Biol. Ther. 15 1647-1651 (2015)

138. Wang, L. et al. Evaluation of candidate vaccine approaches for MERS-CoV. Nat. Commun. 6, 7712 (2015).

139. Lan, J. et al. Recombinant receptor binding domain protein induces partial protective immunity in rhesus macaques against Middle East respiratory syndrome coronavirus challenge. EBioMedicine 2, 1438-1446 (2015).

140. Muthumani, K. et al. A synthetic consensus anti-spike protein DNA vaccine induces protective immunity against Middle East respiratory syndrome coronavirus in nonhuman primates. Sci. Transl Med. 7, 301ra132 (2015).

141. Mastalerz-Migas, A., Bujnowska-Fedak, M. \& Brydak, L. B. Immune efficacy of first and repeat trivalent influenza vaccine in healthy subjects and hemodialysis patients. Adv. Exp. Med. Biol. 836 47-54 (2015)

142. Muller, M. A. et al. Presence of Middle East respiratory syndrome coronavirus antibodies in Saudi Arabia: a nationwide, cross-sectional, serological study. Lancet Infect. Dis. 15, 629 (2015).

143. Haagmans, B. L. et al. An orthopoxvirus-based vaccine reduces virus excretion after MERS-CoV infection in dromedary camels. Science 351, 77-8 (2016).

The finding that vaccination of dromedary camels reduces MERS-CoV shedding on infection, which provides a proof-of-principle for the vaccination of dromedary camels to block zoonotic transmission.

144. Assiri, A. et al. Epidemiological, demographic, and clinical characteristics of 47 cases of Middle East respiratory syndrome coronavirus disease from Saud Arabia: a descriptive study. Lancet Infect. Dis. 13 752-761 (2013)

A report of the clinical presentation of MERS in patients in Saudi Arabia.

145. Leung, G. M. et al. The epidemiology of severe acute respiratory syndrome in the 2003 Hong Kong epidemic: an analysis of all 1755 patients. Ann. Intern. Med. 141, 662-673 (2004)

146. Zumla, A., Hui, D. S. \& Perlman, S. Middle East respiratory syndrome. Lancet 386, 995-1007 (2015)

147. Al-Abdallat, M. M. et al. Hospital-associated outbreak of Middle East respiratory syndrome coronavirus: a serologic, epidemiologic, and clinical description. Clin. Infect. Dis. 59, 1225-1233 (2014).

148. Saad, M. et al. Clinical aspects and outcomes of 70 patients with Middle East respiratory syndrome coronavirus infection: a single-center experience in Saudi Arabia. Int. J. Infect. Dis. 29, 301-306 (2014).

149. Memish, Z. A. et al. Respiratory tract samples, viral load, and genome fraction yield in patients with Middle East respiratory syndrome. J. Infect. Dis. 210, 1590-1594 (2014).

150. Feikin, D. R. et al. Association of higher MERS-CoV virus load with severe disease and death, Saudi Arabia 2014. Emerg. Infect. Dis. 21, 2029-2035 (2015).

151. Majumder, M. S., Kluberg, S. A., Mekaru, S. R. ¿ Brownstein, J. S. Mortality risk factors for Middle East respiratory syndrome outbreak, South Korea, 2015. Emerg. Infect. Dis. 21, 2088-2090 (2015).

152. Gretebeck, L. M. \& Subbarao, K. Animal models for SARS and MERS coronaviruses. Curr. Opin. Virol. 13 123-129 (2015).

153. Munster, V. J. et al. Replication and shedding of MERS-CoV in Jamaican fruit bats (Artibeus jamaicensis). Sci. Rep. 6, 21878 (2016)

154. Lau, S. K. et al. Severe acute respiratory syndrome coronavirus-like virus in Chinese horseshoe bats. Proc. Natl Acad. Sci. USA 102, 14040-14045 (2005).

155. Li, W. et al. Bats are natural reservoirs of SARS-like coronaviruses. Science 310, 676-679 (2005)

156. Wu, D. et al. Civets are equally susceptible to experimental infection by two different severe acute respiratory syndrome coronavirus isolates. J. Virol. 79, 2620-2625 (2005)

157. Adney, D. R. et al. Replication and shedding of MERS$\mathrm{CoV}$ in upper respiratory tract of inoculated dromedary camels. Emerg. Infect. Dis. 20, 1999-2005 (2014). The first description of MERS-CoV replication and shedding in the respiratory tract of dromedary camels, which suggests that MERS-CoV infects the upper respiratory tract in dromedary camels.

158. Becker M. M et al Synthetic recombinant bat SARS-like coronavirus is infectious in cultured cells and in mice. Proc. Natl Acad. Sci. USA 105 19944-19949 (2008).

159. Menachery, V. D. et al. SARS-like WIV1-CoV poised for human emergence. Proc. Natl Acad. Sci. USA 113 3048-3053 (2016).

\section{Acknowledgements}

The work was supported by the Intramural Research Program of the National Institute of Allergy and Infectious Diseases (NIAID), US National Institutes of Health.

Competing interests statement

The authors declare no competing interests. 